
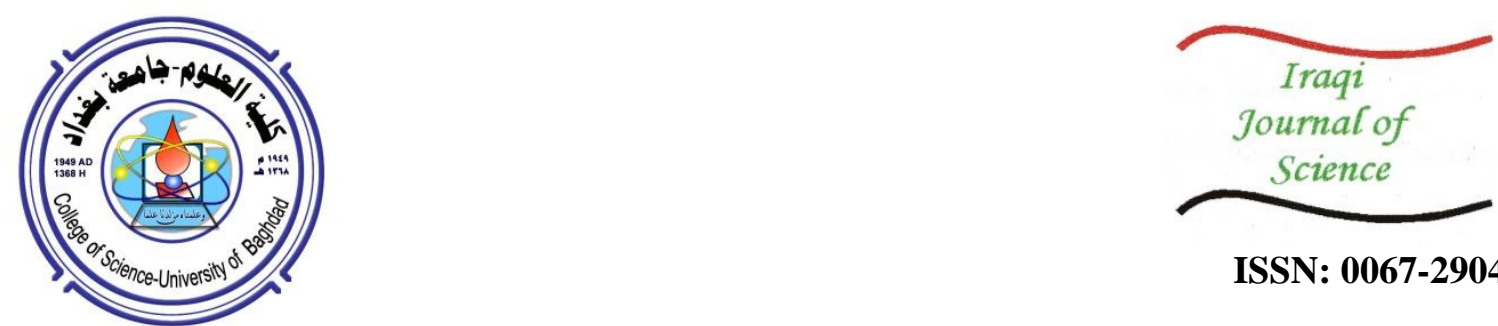

ISSN: 0067-2904

\title{
Interpolation and Statistical Analysis for Evaluation of Global Earth Gravity Models Based on GPS and Orthometric Heights in the Middle of Iraq
}

\author{
Aysar Jameel Abdalkadhum Aljanbi ${ }^{* 1}$, Hayder Dibs ${ }^{1}$, Bashar H. Alyasery ${ }^{3,2}$ \\ ${ }^{1}$ Department of Hydraulic Structures Engineering, Water Resources Engineering College, Al-Qasim Green \\ University, Babylon, Iraq. \\ ${ }^{2}$ Department of Structural Engineering and Water Resources, Faculty of Engineering, University of Kufa, Najaf, \\ Iraq. \\ ${ }^{3}$ Department of Civil Engineering, University of Technology, Baghdad, Iraq \\ Received: $31 / 7 / 2019$ \\ Accepted: 19/11/2019

\begin{abstract}
The regions around the world need to perform their results based on the local geoid. However, each region has different ground topography based on the amount of gravity in this region. Nowadays, the recent global Earth's gravity model of 2008 is successfully used for different purposes in geosciences research. This research presents an overview of the preliminary evaluation results of the new Earth Gravitation Model (EGM08) in the middle of Iraq. For completeness, the evaluation tests were also performed for EGM96 by examining 31 stations distributed over four Iraqi provinces. The national orthometric heights were compared with the GPS /leveling data obtained from these stations. This study illustrated that the GPS /leveling based on EGM08 data was better than that based on EGM96 data in terms of reducing the root mean square error (RMSE) of the differences between the orthometric heights and GPS/leveling data. The standard deviation (SD) values for the national orthometric heights and GPS heights were about 4 and $26 \mathrm{~cm}$, respectively. The results also show that there is a small difference in hight ranged $(0.0013-0.1333 \mathrm{~m})$ in Karbala, $(0.0023-0.0062 \mathrm{~m})$, in Najaf and $(0.0173-0.0703$ $\mathrm{m})$, in Babylon. Due to the flat area, better results were obtained in Karbala and Najaf than Babylon. The EGM08 geoid method has shown to yield very close results to reality for various projects, thus its accuracy is acceptable.
\end{abstract}

Keywords: EGM08 geoid, EGM96 geoid, ellipsoidal and orthometric heights, GPS leveling.
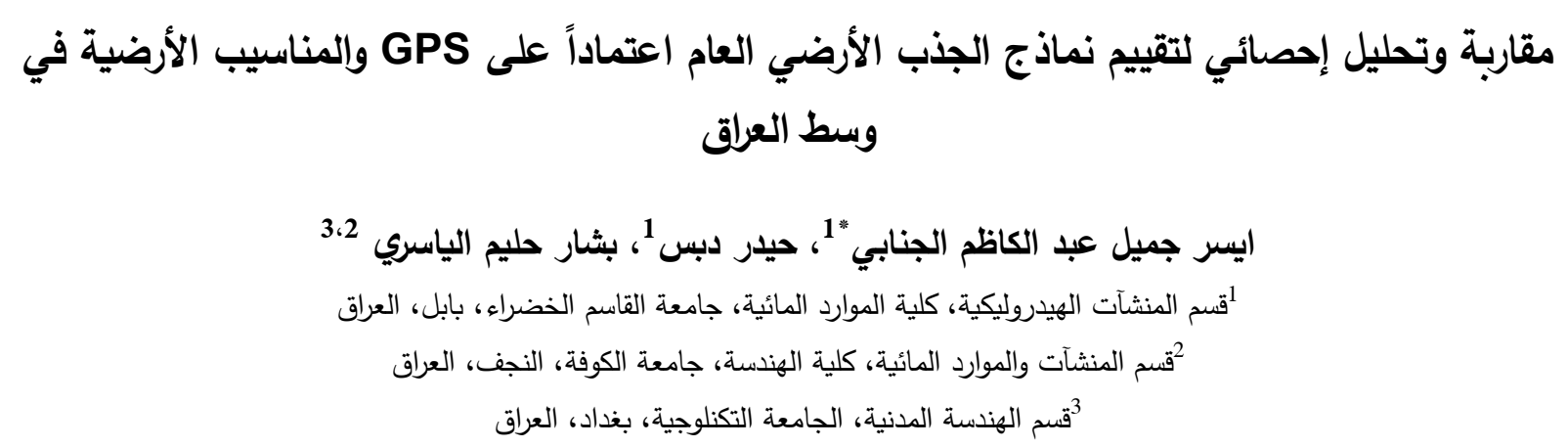


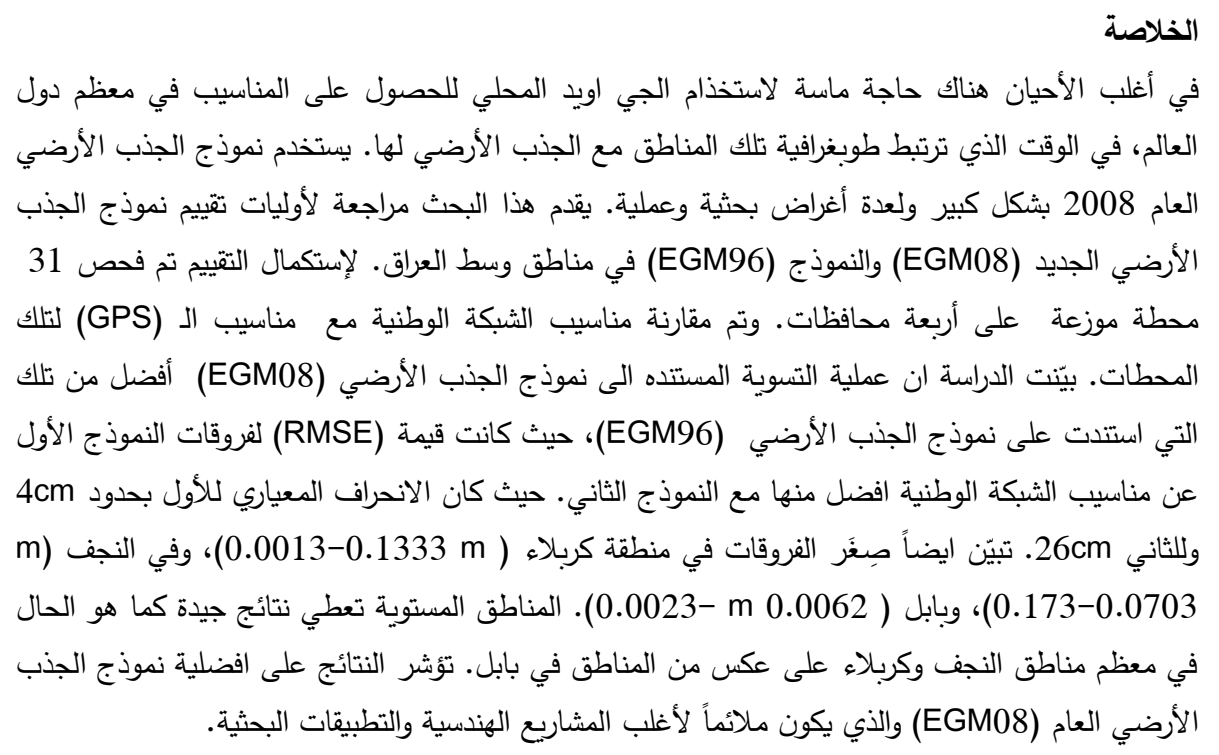

\section{INTRODUCTION}

The Earth Gravitational Model (EGM08) is the modern version of a series of geopotential models developed under the management of the US National Geospatial-Intelligence Agency (NGA) [1-4]. It incorporates harmonic coefficients that are derived from the GRACE satellite mission, marine gravity anomalies derived from satellite altimetry, and a comprehensive set of terrestrial gravity anomalies. EGM08 offers an unprecedented level of spatial resolution $(\sim 9 \mathrm{~km})$ for the recovery of any gravitational field function over the entire globe, with a degree and order of 2159 and with additional Spherical Coeftients ( SHCs) that extend up to a degree of 2190 and an order of 2159 [5- 7, 4]. Since it has been released, EGM08 has become the standard geopotential model used for many applications, including geoid modeling. Also, it has been evaluated in a number of countries using various methods [8]. The evaluation and quality assessment of the EGM08 is important for being used in various geodetic and other scientific applications at global and regional scales. The estimation of the EGM08 is based on the comparisons with other external data. This data may include GNSS/leveling observations, airborne and surface gravity, sea surface topography, and deflections of the vertical values. To convert heights of GPS ellipsoid into orthometric heights, we need to know the geometric and mathematical relationship between ellipsoid and geoid data. Figure-1 illustrates the mathematical relationship between the ellipsoid and orthometric height. In equation (1), it is clear how to convert ellipsoid height to orthometric height utilizing geoid undulation [9].

$$
\mathrm{H}=\mathrm{h}-\mathrm{N}
$$

where $\mathrm{h}$ represents the ellipsoid height, and $\mathrm{H}$ and $\mathrm{N}$ refer to orthometric height and geoid undulation, respectively.

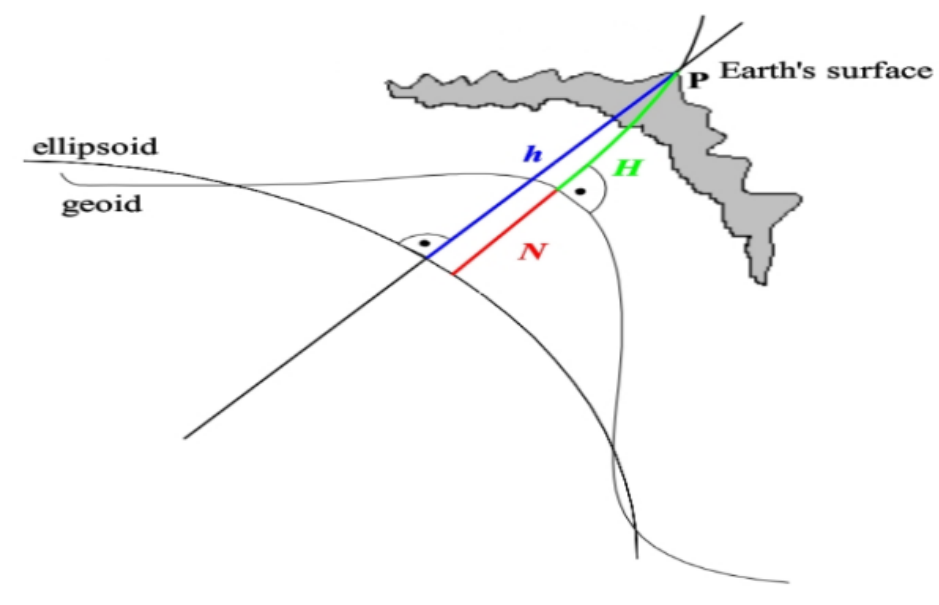

Figure1-The geometric relationship between ellipsoidal and geoid orthometric height[10]. 
Geoid refers to the earth's surface that relates to the earth's gravity filed represented by mean sea level (MSL). This data is used as reference data for physical height systems. The geoid computation is very important in the calculation of geodetic computation [10]. Recently, the computation of the local geoid became very important for research needs in geodesy science. Therefore, several geo-models started to develop and present the geoids height in the global form. It is possible to obtain a geoid height for any object throughout the world with an accuracy that reaches to $30 \mathrm{~cm}$ using the modern geoid models [11, 12]. The development in the global positioning system (GPS) resulted in the appearance of new facilities of positioning technology and instruments of location determination. With new positioning techniques, it is possible to provide a geoid determination with high accuracy of calculation that will lead to replacing the geometric leveling by GPS. On the other hand, when considering the geo-models accuracy to that of GPS height, it seems that it does not match the required GPS height accuracy. Therefore, there is a need to develop a new local geoid model. Several approaches and methods were developed to obtain a local geoid, all of which can be divided into two basic methods, as described by Rapp (1997) and indicated in the followed sections. The geometric method has been used in flat and relatively small areas. Therefore, the local geoid calculation and determination can be computed from the combination of the leveling heights with the height from GPS $[13,12]$. This approach has been used widely throughout the world in engineering applications and projects, and it is satisfied within an area of about $1000 \mathrm{~km}^{2}$ [12]. The accuracy of the geoid model obtained from the geometric method is based on several factors, including the reference station of each of GPS along with the leveling stations and their homogeneity and distribution. The distribution of all stations should be as homogeneous as possible in that area model, while the selection of these stations should capture the probable change that can happen in the geoid earth's surface [14].

The gravimetric method is used to compute the geoid from using the gravity measurements [15]. The remove restore method is widely applied to determine the gravimetric geoid model [10]. It is a mathematical and impractical method to compute the gravimetric geoid of the earth's surface, while a removal technique is computed by the calculation of the components of a long-wavelength as a gravity anomaly $[10,15]$. This study focuses on the evaluation of EGM08 using GNSS/leveling over 31 stations in four provinces (Babylon, Najaf, AL-Anbar and Karbala) in the middle of Iraq. In addition, an evaluation of the results of the EGM96 will be presented for comparison purposes.

\section{Description of the Study Area}

The study area in part of the middle of Iraq. The 31 stations are distributed in four provinces; six stations in Babylon, eleven stations in Najaf, two stations in AL-Anbar and twelve stations in Karbala. Najaf is an old city in southern Iraq, it is about $160 \mathrm{~km}$ to the south of Baghdad. It has a population of 1000,000 people in 2013. Najaf is known as one of the old important teaching centres of the Islamic world and surrounded by five Iraqi provinces while also bordered from the south by Saudi Arabia. Karbala is located about $100 \mathrm{~km}$ in the south-west of the capital of Iraq (Baghdad) with a population of about 700,000 people in 2015. Kerbala is surrounded by three provinces. Babylon was a kingdom in the ancient Mesopotamia between the $18^{\text {th }}-6^{\text {th }}$ centuries BC. It was built on the Euphrates river and divided into equal parts built along its right and left banks. It has a population of over 200,000 and located about $90 \mathrm{~km}$ south of Baghdad. Al-Anbar province has the largest area between the Iraqi provinces. AL-Anbar shares its boundary with Syria, Jordan, and Saudi Arabia. Ramadi is the capital of AL-Anbar [16]. 


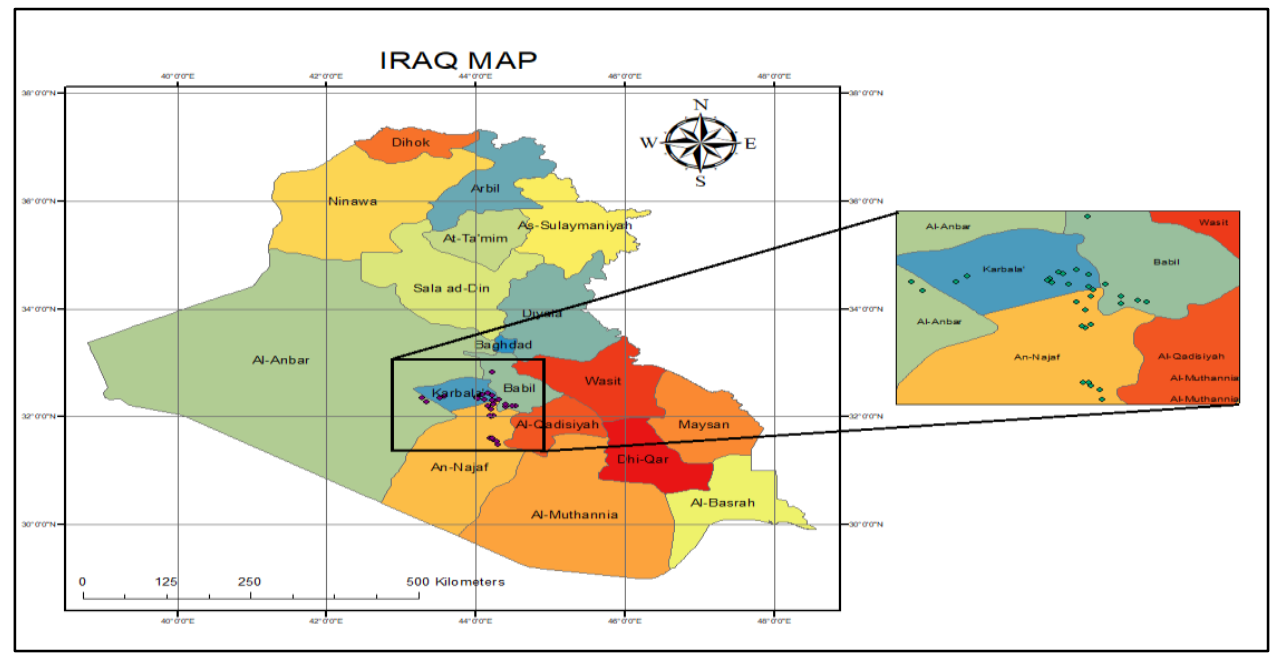

Figure 2-Locations of the 31 stations distributed in the four provinces.

\section{Collecting And Processing of Dataset}

The orthometric heights for the 31 stations were obtained from the State Commission survey in Iraq. As the reference for these heights was in the south of Iraq (FAW), the datum was called Mean Sea Level (MSL FAW), this data is shown in Table1. On the other hand, the differential global positioning system (GPS) type Topcon (GR3) GNSS receivers were used static method to observed 31 stations, each point observed 5 hours. The RINEX data of the stations were then submitted to the opus online GPS Processing Service. The data were computed and corrected by using the Bernese GPS software. All computed coordinates were based on the ITRF00 reference frame. All our evaluation results that are presented in the next section refer to the thirty-one stations. Table 1 illustrates the Final geodetic, IGRS ellipsoid, and known heights concerning EGM08 and EGM96 geoid height.

Table 1-Final geodetic, IGRS ellipsoid, (ITRF00 data) coordinates, and known heights with EGM08 \& EGM96 geoid heights.

\begin{tabular}{lllllll}
\hline No. & $\begin{array}{l}\text { LAT. } \\
\text { (DMS) }\end{array}$ & $\begin{array}{l}\text { LONG. } \\
(\mathrm{DMS})\end{array}$ & $\begin{array}{l}\text { h(WGS84) } \\
(\mathrm{M})\end{array}$ & $\begin{array}{l}\text { (EGM08) } \\
(\mathrm{M})\end{array}$ & $\begin{array}{l}\text { (EGM96) } \\
(\mathrm{M})\end{array}$ & $\begin{array}{l}\text { Ortho. Metric } \\
\text { Height }(\mathrm{M} . \mathrm{S} . \mathrm{L} \\
\text { FAW) }(\mathrm{M})\end{array}$ \\
\hline 1 & 322816.51048 & 442518.18710 & 25.551 & 28.333 & 29.457 & 28.31844 \\
\hline 2 & 322334.71618 & $\begin{array}{l}4424 \\
06.39261\end{array}$ & 23.063 & 25.812 & 26.963 & 25.73618 \\
\hline 3 & 323049.60963 & 442328.97435 & 24.911 & 27.548 & 28.625 & 27.53046 \\
\hline 4 & 323928.83199 & 442354.91221 & 28.535 & 31.072 & 32.047 & 31.03114 \\
\hline 5 & 323239.21673 & 443241.96020 & 24.052 & 27.240 & 28.398 & 27.22567 \\
\hline 6 & 324343.82643 & 441617.08605 & 31.439 & 33.423 & 34.280 & 33.40214 \\
\hline 7 & 3218 & 444056.90877 & 20.373 & 24.265 & 25.586 & 24.21030 \\
& 08.11203 & & & & & \\
\hline 8 & 322354.27342 & 444018.05617 & 22.066 & 25.825 & 27.168 & 25.75015 \\
\hline 9 & 321937.22034 & 445459.50742 & 17.583 & 22.259 & 23.838 & 22.25379 \\
\hline 10 & 3213 & 442156.56298 & 21.738 & 24.474 & 25.562 & 24.44866 \\
& 03.14949 & & & & & \\
\hline 11 & 322056.66760 & 444945.79160 & 20.697 & 25.058 & 26.545 & 25.01696 \\
\hline 12 & 3200 & 442112.31910 & 37.491 & 40.297 & 41.232 & 40.26577 \\
& 43.50337 & & & & & \\
\hline 13 & 315910.52747 & 442033.86195 & 49.689 & 52.460 & 53.377 & 52.42405 \\
\hline 14 & 320204.5559 & 442435.96688 & 21.437 & 24.457 & 25.427 & 24.44740 \\
\hline 15 & 315720.31256 & 442416.23579 & 36.532 & 39.548 & 40.473 & 39.54180 \\
\hline 16 & 32820.69619 & 442247.82714 & 25.893 & 28.744 & 29.779 & 28.73160 \\
\hline 17 & 315949.27909 & 442326.57754 & 30.795 & 33.751 & 34.691 & 33.75330 \\
\hline 18 & 321908.6384 & 441626.63658 & 24.129 & 26.413 & 27.508 & 26.42540 \\
\hline
\end{tabular}




\begin{tabular}{lllllll}
\hline 19 & 314738.26162 & 443010.14683 & 17.578 & 20.922 & 21.897 & 20.94360 \\
\hline 20 & 320134.8427 & 441919.52634 & 44.863 & 47.540 & 48.474 & 47.55330 \\
\hline 21 & 315414.49598 & 442933.33702 & 18.367 & 21.719 & 22.665 & 21.71180 \\
\hline 22 & 323615.53439 & 440201.72497 & 26.080 & 27.223 & 28.053 & 27.31026 \\
\hline 23 & 323536.80848 & $\begin{array}{l}4401 \\
42.01011\end{array}$ & 29.808 & 30.929 & 31.771 & 30.99998 \\
\hline 24 & 323848.13267 & 435857.36437 & 27.509 & 28.441 & 29.193 & 28.39047 \\
\hline 25 & 324135.00900 & 440754.33690 & 27.855 & 29.344 & 30.138 & 29.28609 \\
\hline 26 & 324029.16872 & 440948.67799 & 28.871 & 30.490 & 31.323 & 30.47820 \\
\hline 27 & 323241.63892 & 441256.53724 & 27.229 & 29.139 & 30.108 & 29.11690 \\
\hline 28 & 323345.92812 & 440344.25230 & 29.264 & 30.531 & 31.423 & 30.60181 \\
\hline 29 & 323421.15531 & 432855.46546 & 60.085 & 58.727 & 59.626 & 58.79625 \\
\hline 30 & 322753.63649 & 433451.87032 & 73.464 & 72.612 & 73.568 & 72.61974 \\
\hline 31 & 323412.94528 & 435217.99133 & 64.477 & 64.941 & 65.768 & 64.93964 \\
\hline
\end{tabular}

\section{Data Compression Procedure}

The basic relationship between geoid, ellipsoidal, and orthometric heights is given by the following simple equation $[11,17,9]$ :

$$
h=H+N
$$

where h, $\mathrm{H}$ and $\mathrm{N}$ are ellipsoidal, orthometric and geoid heights, respectively. Based on the known heights and computed ellipsoidal heights, geoid heights were computed at the 31 GNSS/leveling stations by rearranging equation (3) in [11, 9, 18, 19]. [20] explained local determination of geoid is necessary for better accuracy of the orthometric height from GPS.

$$
N^{G P S}=h-H
$$

The values shown in Table 1 offered the dataset upon which the evaluation tests were performed. For EGM08, the geoid height values of the 31 GNSS/leveling stations with respect to WGS84 were determined using the FORTRAN harmonic synthesis program (hsynth-WGS84) together with the EGM2008 Tide Free Spherical Harmonic Coefficients and its associated Correction Model. To run this program, an input file with the latitudes and longitudes of the 31 stations must be stored in the same folder as the executable file of the program. After running the program, an output file containing the geoid height values for all the stations is automatically stored in the same folder as the program. The output file can then be opened using Notepad or Excel. For EGM96, the geoid height values were computed online using the NGA EGM96 Geoid Calculator found in the following website: (http://earth-info.nga.mil/wgs84/gravitymod/egm96/intpt.html). This requires the manual input of the latitude and longitude for each individual point and then by clicking "calculate the geoid height" the value is automatically computed and displayed.

\section{The Interpolation and Statistical Analysis Results}

In this section, we perform an evaluation for the differences of the geoid heights derived from EGM08 and EGM96 versus the geoid heights from GNSS/leveling, using statistical analysis. We compare the results to obtain the most accurate result that indicates which earth gravitation model has more accuracy than the other. In addition, we conduct an interpolation for all obtained stations for EGM08, EGM96, FAW, and WGS84, to evaluate the differences in heights and to compare the results. Table 2 and Figures- 3 and 4 show the geoid height differences for the 31 GPS stations, while Table 3 demonstrates the summary of statistical results. The results show that the EGM08 provides the most consistent agreement with the GNSS/leveling data over the stations. The differences with the orthometric heights ranged $(0.0013-0.1333 \mathrm{~m})$ in Karbala , $(0.0023-0.0062 \mathrm{~m})$ in Najaf, and $(0.0173-0.0703 \mathrm{~m})$ in Babylon. The flat area in Karbala and Najaf produced better results than the area in Babylon. Figure- 4 illustrates the results of the 31 stations where EGM08 provided the most convenient agreement with the GNSS/leveling data over the stations, and the differences with the orthometric heights were minimal. From Figure- 4, it is clear how close the EGM08 data to the orthometric height, as indicated in blue and green colors, compared to the EGM96 data that is representing in the red line and shown to be far from the data of the orthometric height. All the statistical results are indicated in Tables 2 and 3. 

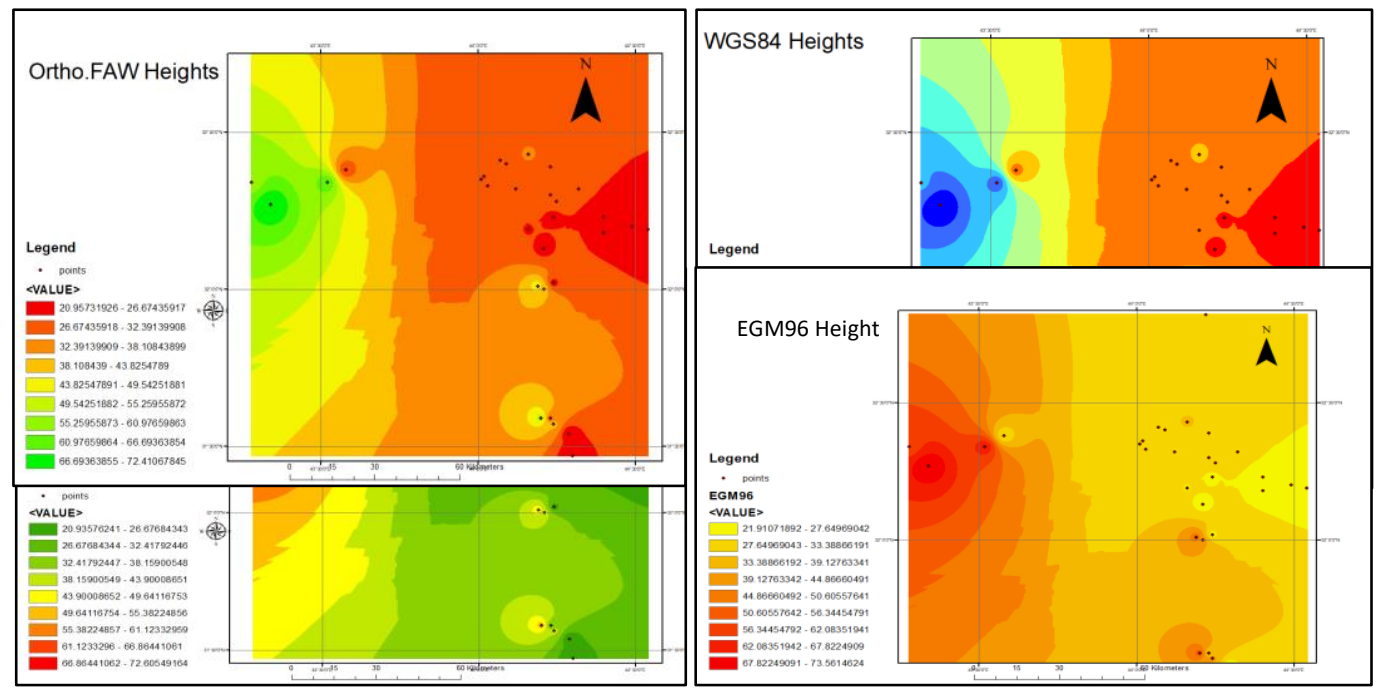

Figure 3-The interpolation of the EGM08, EGM96, FAW, and WGS84 heights.

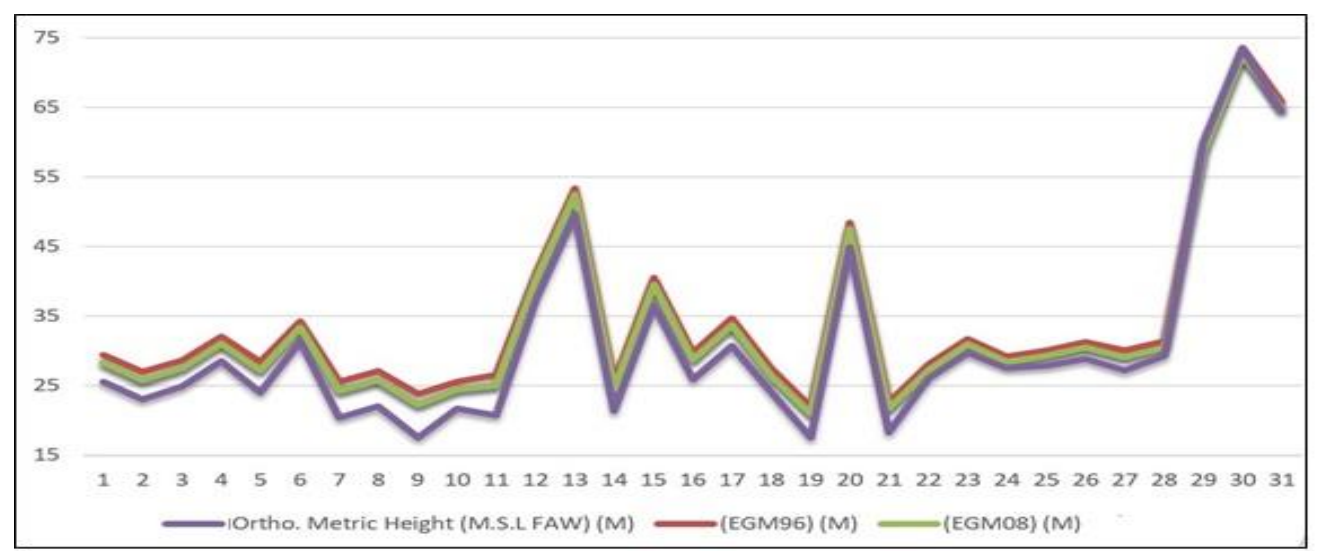

Figure 4- Differences among orthometric heights (M.S.L FAW), EGM96, and EGM08.

Table 2-EGM08 and EGM96 geoid height values and $\mathrm{N}^{\text {GPS }}$ values for the 31 GNSS/leveling.

\begin{tabular}{cccccc}
\hline No. & $\begin{array}{c}\mathbf{N}(\mathbf{E G M 0 8}) \\
(\mathbf{M})\end{array}$ & $\begin{array}{c}\mathbf{N}(\mathbf{E G M 9 6}) \\
(\mathbf{M})\end{array}$ & $\mathbf{N}^{\mathbf{G P S}}=\mathbf{h}-\mathbf{H}(\mathbf{M})$ & $\mathbf{N}^{\mathbf{G P S}}-\mathbf{N}^{\mathbf{e g m 0 8}}(\mathbf{M})$ & $\mathbf{N}^{\mathbf{G P S}}-\mathbf{N}^{\mathbf{e g m} 96}(\mathbf{M})$ \\
\hline 1 & -2.782 & -3.906 & -2.76744 & 0.01456 & 1.13850 \\
\hline 2 & -2.749 & -3.900 & -2.67318 & 0.07582 & 1.22682 \\
\hline 3 & -2.637 & -3.714 & -2.61946 & 0.01754 & 1.09454 \\
\hline 4 & -2.537 & -3.512 & -2.49614 & 0.04086 & 1.01586 \\
\hline 5 & -3.188 & -4.346 & -3.17367 & 0.01433 & 1.11723 \\
\hline 6 & -1.984 & -2.841 & -1.96314 & 0.02086 & 0.87786 \\
\hline 7 & -3.892 & -5.213 & -3.83730 & 0.05470 & 1.37570 \\
\hline 8 & -3.759 & -5.102 & -3.68415 & 0.07485 & 1.41785 \\
\hline 9 & -4.676 & -6.255 & -4.67079 & 0.00521 & 1.58421 \\
\hline 10 & -2.736 & -3.824 & -2.71066 & 0.02534 & 1.11334 \\
\hline 11 & -4.361 & -5.848 & -4.31996 & 0.04104 & 1.52804 \\
\hline 12 & -2.806 & -3.741 & -2.77477 & 0.03123 & 0.96623 \\
\hline 13 & -2.771 & -3.688 & -2.73505 & 0.03595 & 0.95295 \\
\hline 14 & -3.020 & -3.990 & -3.01040 & 0.00960 & 0.97960 \\
\hline 15 & -3.016 & -3.941 & -3.00980 & 0.00620 & 0.93120 \\
\hline 16 & -2.881 & -3.886 & -2.83860 & 0.04240 & 1.04740 \\
\hline 17 & -2.956 & -3.896 & -2.95830 & 0.00230 & 0.93770 \\
\hline 18 & -2.284 & -3.379 & -2.29640 & -0.01200 & 1.08260 \\
\hline
\end{tabular}




\begin{tabular}{llllll}
\hline 19 & -3.344 & -4.319 & -3.36560 & -0.02160 & 0.95340 \\
\hline 20 & -2.677 & -3.611 & -2.69030 & -0.01330 & 0.92070 \\
\hline 21 & -3.352 & -4.298 & -3.34480 & 0.007200 & 0.95320 \\
\hline 22 & -1.143 & -1.397 & -1.23026 & -0.08726 & 0.16674 \\
\hline 23 & -1.121 & -1.963 & -1.19198 & -0.07098 & 0.77102 \\
\hline 24 & -0.932 & -1.684 & -0.88147 & 0.050530 & 0.80253 \\
\hline 25 & -1.489 & -2.283 & -1.43109 & 0.057910 & 0.85191 \\
\hline 26 & -1.619 & -2.452 & -1.60720 & 0.011800 & 0.84480 \\
\hline 27 & -1.910 & -2.879 & -1.88790 & 0.022100 & 0.98810 \\
\hline 28 & -1.267 & -2.159 & -1.13370 & 0.133300 & 1.02530 \\
\hline 29 & 1.358 & 0.4590 & 1.28875 & 0.069250 & 0.82975 \\
\hline 30 & 0.852 & -0.104 & 0.84426 & 0.007740 & 0.94826 \\
\hline 31 & -0.464 & -1.291 & -0.46264 & -0.00136 & 0.82836 \\
\hline
\end{tabular}

Table 3-Statistics of the differences $\mathrm{N}^{\mathrm{GPS}}-\mathrm{N}$ at the 31 GPS stations.

\begin{tabular}{cccccc}
\hline EGMs & $\begin{array}{c}\text { Minimum } \\
(\mathbf{M})\end{array}$ & $\begin{array}{c}\text { Maximum } \\
(\mathbf{M})\end{array}$ & Mean $(\mathbf{M})$ & $\begin{array}{c}\text { Standard } \\
\text { deviation }(\mathbf{M})\end{array}$ & RMS (M) \\
\hline EGM08 & -0.00136 & 0.1333 & 0.0215 & 0.0417 & 0.0075 \\
\hline EGM96 & 0.16674 & 1.58421 & 1.0088 & 0.2627 & 0.0472 \\
\hline
\end{tabular}

\section{Conclusions}

The countries throughout the world need to refer to specific geoid data in their surveying measurements. The new Earth Gravitation Model must be examined in our region to evaluate the satisfaction level of using this EGM in Iraq. The data of GPS/leveling with EGM08 indicates that EGM08 may be used as an orthometric height measurement with an accuracy of $<4 \mathrm{~cm}$ in the middle of Iraq region and offers a reasonable and good platform to transform data from ellipsoid to local. However, local determination of geoid is necessary for better accuracy of the orthometric height from GPS. Small differences in heights were recorded and ranged $(0.0013-0.1333 \mathrm{~m})$ in Karbala, $(0.0023-$ $0.0062 \mathrm{~m})$ in Najaf, and $(0.0173-0.0703 \mathrm{~m})$ in Babylon. The flat area in Karbala and Najaf showed better results than the area in Babylon. This conclusion was made based on studying the relation between national orthometric heights and orthometric heights. The EGM08 geoid method has shown to yield very close results to reality for various projects, thus its accuracy is acceptable. This research proves a match between the geoid and the spheroid in these regions, so the use of traditional leveling gave approximately similar results to that of GPS leveling in some of the studied regions.

\section{Acknowledgments}

The authors are grateful to to the State Commission of Survey in Iraq. The authors would also like to thank the reviewers.

\section{REFERENCES}

1. Kearey, P., Michael, B. and Hill, I. 2002. An Introduction to geophysical exploration, 3 Ed., Blackwell Science Ltd., 262p. rd

2. Pavlis, N.K., Holmes, S.A., Kenyon, S.C. and Factor, J.K. 2008. An Earth Gravitational Model to degree 2160: EGM2008. Presented at the 2008 General Assembly of the European Geosciences Union, Vienna, Austria, April 13-18, 2

3. Dawod, M. G. 2012. Principles of Geodetic Surveys and GPS, (In Arabic), Holly Makka Saudi Arabia, pp: 42-44.

4. Pavlis, N. K., Holmes S. A., Kenyon S. C. and Factor J. K. 2012. "The development and evaluation of the Earth Gravitational Model 2008 (EGM2008)", Journal of Geophysical Research: Solid Earth (1978-2012), April, 117(B4).

5. Lowrie, W. 2007. Fundamental of geophysics, Blackwell Science Ltd, 2nd edition,132p.

6. Kotsakis, C. and Katsambalos, K. 2010. Quality analysis of Global Geopotential Models at 1542 GNSS/leveling Benchmarks over the Hellenic Mainland, Survey Review, 42(318): 327-344 (October 2010). 
7. Hirt, C. 2011. "Assessment of EGM2008 over Germany Using Accurate Quasigeoid Heights from Vertical Deflections, GCG05 and GPS/Levelling", Zeitschrift fuer Geodaesie, Geoinformation und Landmanagement (zfv), 136(3): 138-149

8. Seeber, G. 2003. "Satellite Geodesy", 2nd completely revised and extended edition, Walter de Gruyter, Berlin, New York.

9. Martensson, S. G. 2002. Height Determination by GPS -Accuracy with Respect to Different Geoid Models inSweden, FIG XXII International Congress, pp19-26.

10. Heiskanen,W. A. and Moritz, H. 1967. "Physical Geodesy", Textbook, W.H. Freeman and Company.

11. Rummel, R. 1992. GPS, Heights and the of the geoid, Geodetical Info Magazine, pp56-57

12. Chen, Y. and Yang, Z. 2001. "A Hybrid Method to Determine the Hong Kong Geoid", International Conference, FIG Working Week 2001, Seoul, Korea, 6-11 May.

13. Featherstone, W. E., Denith, M. S. and Kirby J. F. 1998. "Strategies for the accurate determination of Orthometric Heights", Survey Review, 34(267): 278-296.

14. Erol, B. and Çelik, R.N. 2004. "Precise Local Geoid Determination to Make GPS Technique More Effective in Practical Applications of Geodesy", International Conference, FIG Working Week 2004, Athens, Greece, May 22-27.

15. Rene F. and Tscherning, C.C. 2008. "An overview manual for the GRAVSOFT Geodetic Gravity Field Modelling Programs", 2.edition, August 2008.

16. Anthony H. Cordesman; Sam Khazai. 2014. Iraq in Crisis. Rowman \& Littlefield. p. 319. ISBN 9781442228566. 2014.

17. Zilkoski, D. B., Carlson, E. E. and Smith, C. L. 2001. A Guide for Establishing GPS-Derived Orthometric Heights (Standards: $2 \mathrm{~cm}$ and $5 \mathrm{~cm}$ ), National Geodetic Survey, pp45-46.

18. El-Ashquer, M. A., Zahran, K. H., El-Fiky, G. S., and Salama, I. M 2010. Accuracy Assessment of GPS leveling Applications: Case Study North West Lake Nasser, Aswan, Egypt, Scientific Bulletin Faculty of Engineering Ain Shams University,pp76-77.

19. Bashar H. " Leveling By Differential Global Position System ( Case Study), International Journal of Scientific \& Engineering Research, 7(9), September-2016, ISSN 2229-5518.

20. Ayser J. 2015. "A Comparison of National Orthometric Heights with DGPS/Leveling and ITRF00 Datum with WGS84 (EGM08) Geoid" , International Journal of Advancements in Research \& Technology, 4(11), November, ISSN 2278-7763. 